\title{
APLICAÇÃO DA ERGONOMIA NO ENSINO DO DESIGN: METODOLOGIA REFLEXIVA NO ESTUDO DA ANTROPOMETRIA E DO POSTO DE TRABALHO.
}

\author{
SILVA, Anna Lúcia dos Santos Vieira e Silva (1); \\ SANTIAGO, Zilsa Maria Pinto (2) \\ (1) Universidade Federal do Ceará, Doutora \\ e-mail:lilu@dau.ufc.br \\ (2) Universidade Federal do Ceará, Doutora \\ e-mail:zilsasantiago@gmail.com
}

\begin{abstract}
RESUMO
No contexto de graduação em Design, foi desenvolvido um método de ensino diferenciado na disciplina Ergonomia 1. O artigo analisa parte do conteúdo programático: o estudo da antropometria, análise ergonômica de um posto de trabalho e o projeto de sua adequação às necessidades diagnosticadas. O diferencial é a referência adotada que implica a realidade cotidiana dos alunos em atividades relativas às demandas da universidade. A metodologia tratou do levantamento antropométrico dos alunos; análise das condições e ambiente de trabalho em casa; e o projeto de reformulação ou transformação do contexto analisado, com o objetivo de qualificar seu sistema ergonômico.
\end{abstract}

Palavras chave: metodologias de ensino e aprendizado; ergonomia; design.

\begin{abstract}
On the context of the Design study a distinctive teaching method was developed for the discipline of Ergonomics 1. This article proposes to analyze part of the addressed programmatic content: the study of Anthropometry, the ergonomic analysis of a working space and the project of adjustment of this working space according to the perceived needs. The differential here is the adopted reference: the everyday life of the students, and its intrinsic activities regarding the university. The methodology has dealt with the anthropometric survey of the students; the analysis of the conditions of their working spaces at home; and the project of reformulation or adaptation of the analyzed context, with the purpose of bringing quality to the ergonomic system.
\end{abstract}

Keywords: teaching-learning methodology; ergonomics; design.

\section{INTRODUÇÃO}

Em se tratando de um curso de Bacharelado em Design inaugurado em 2012 na Universidade Federal do Ceará, as experiências didáticas foram ao mesmo tempo implementadas e avaliadas ao longo do semestre de forma a se ter um aprimoramento das disciplinas. 
$\mathrm{Na}$ inserção do componente curricular Ergonomia 1, ministrada aos alunos do terceiro semestre, foi desenvolvido pela autoras do artigo um método de ensino diferenciado para a disciplina. Segundo o plano pedagógico do curso, o objetivo é o entendimento da eficácia nas relações entre o homem, a tarefa que executa e os equipamentos de trabalho, para fundamentar os princípios de um sistema ergonômico e habilitar o projeto de objetos ergonômicos em um posterior aprofundamento do sistema.

A proposta deste artigo é analisar parte do conteúdo programático abordado: o estudo da antropometria, a análise ergonômica de um posto de trabalho e o projeto de sua adequação às necessidades diagnosticadas. O diferencial é a referência adotada: a realidade cotidiana dos alunos, que implica atividades relativas às demandas da universidade. Desta forma, a parte inicial deste estudo se caracteriza como pesquisa empírica, em que cada aluno analisa suas próprias tarefas/atividades de forma a reconhecê-las, identificá-las, classificá-las com o objetivo de diagnosticar as condições ergonômicas espaciais, dos mobiliários e dos equipamentos utilizados.

Uma das limitações que nos apresenta é o fato da disciplina ter sido estruturada e oferecida pela primeira vez no curso, bem como os embates que tivemos com a turma. As limitações, paradoxalmente, são também motivação para o desenvolvimento e aprimoramento da disciplina. Isto porque é uma disciplina em que a teoria e a prática se encontram imbricadas. Neste sentido, para que a se possa avançar tanto no conteúdo como no seu entendimento por parte dos alunos foi necessária a efetiva participação discente na execução das tarefas práticas.

Inicialmente, o estudo da antropometria foi apresentado e trabalhado em sala de aula tendo como fundamento parâmetros referenciados em Dreyfuss, 2010; PANERO e ZELNIK, 2003, onde os vinte e três alunos fizeram uma prática de auferir suas medidas corpóreas e registrá-las sobrepostas em pranchas de papel colocadas previamente nas paredes da sala de aula, separados por dois grupos: feminino e masculino.

Neste trabalho didático que envolveu a realidade de cada aluno como uma aplicação prática dos princípios ergonômicos, tivemos como referência Gomes Filho (2010). Foi possível verificar a assimilação do conteúdo estudado pela experiência do próprio aluno em seu local residencial de estudo, como objeto de pesquisa e reflexão sobre o conteúdo abordado, característica da pesquisa-ação de (TRIPP, 2005; BARBIER, 2002) que o coloca ao mesmo tempo como sujeito da ação, da reflexão e transformação, a que se refere Schön (2000).

\section{DESENVOLVIMENTO}

O artigo aborda duas linhas metodológicas. A primeira diz respeito a metodologia aplicada aos alunos e se desenvolve a partir da proposta de trabalho solicitada pelas professoras. A segunda abrange a classificação e análise das informações a partir dos resultados obtidos.

\subsection{A Pesquisa-ação}

Atualmente algumas metodologias implicam o estudo de situações cotidianas para desenvolver uma investigação em diferentes áreas do conhecimento. Especificamente na área educacional, a pesquisa-ação se volta a estratégias de pesquisa que se direcionam ao aprimoramento do ensino em decorrência dos resultados e do aprendizado dos alunos.

A pesquisa-ação é um tipo de investigação-ação. Esta, por sua vez, é um termo genérico que se usa para os processos cíclicos que envolvem a qualificação de uma prática a partir de ações e investigações sobre sua realidade intrínseca. 


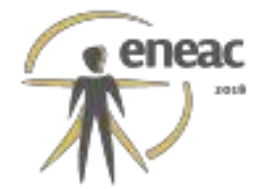

Quatro etapas fundamentam a investigação-ação: o planejamento de uma qualificação em uma situação vigente; a ação para implementar a melhora projetada; monitorar, descrever os efeitos da ação; e avaliar os resultados, para retomar a etapa inicial, promovendo assim um continuum evolutivo e adaptativo. As duas primeiras etapas são ativas e as duas seguintes são investigativas.

\begin{abstract}
Planeja-se, implementa-se, descreve-se e avalia-se uma mudança para a melhora de sua prática, aprendendo mais, no correr do processo, tanto a respeito da prática quanto da própria investigação. A maioria dos processos de melhora segue o mesmo ciclo. A solução de problemas, por exemplo, começa com a identificação do problema, o planejamento de uma solução, sua implementação, seu monitoramento e a avaliação de sua eficácia. (TRIPP, 2005, p. 444-445)
\end{abstract}

Na definição de Donald Tripp (2005, p. 447) a pesquisa-ação "é uma forma de investigaçãoação que utiliza técnicas de pesquisa consagradas para informar a ação que se decide tomar para melhorar a prática". O autor acrescenta a importância de sua integração no âmbito da pesquisa acadêmica, inclusive por seguir os mesmos critérios. Desta forma, se caracteriza tanto pela prática cotidiana quanto pela pesquisa científica. Na pesquisa-ação, a metodologia serve a prática e esta alimenta a investigação, que se volta novamente à prática de forma documentada, intervencionista, reflexiva e compreendida.

\title{
2.2 Ciclos Vivenciados, Teoria e Prática
}

Como conteúdo programado, havia a necessidade de estudar a antropometria, o posto de trabalho, as atividades e objetos/ferramentas de trabalho, como fundamentos e elementos estruturadores do entendimento de um sistema ergonômico.

A primeira etapa abordada na disciplina de ergonomia foi teórica e investigativa. Foram apresentados os fundamentos a partir de uma bibliografia e de artigos acadêmicos e os alunos estudaram o conteúdo. A segunda etapa foi prática, com ênfase à antropometria. Murais de papel foram colados nas paredes da sala de aula, turma foi dividida em grupos por gênero para a definição de perfis diferenciados de um grupo de vinte e três pessoas. Os alunos se situaram para efetuar suas medições sobrepostas e coloridas. Foram realizadas medidas frontais, laterais com referência nas articulações. Dois murais, um com variação de medidas femininas e um com variação medidas masculinas.

Figura 1: Processo do levantamento antropométrico dos alunos

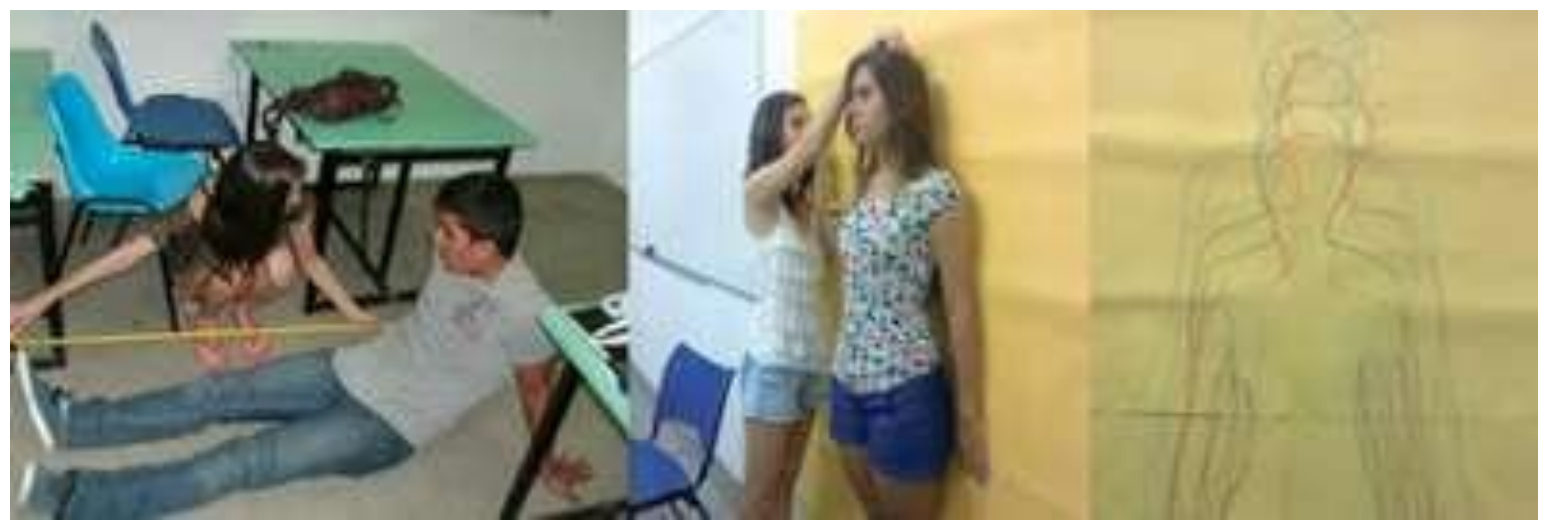

Fonte: Elaborado pelos autores, com base na pesquisa realizada 
Com a experiência das diferentes medidas, os alunos receberam outra informação teórica, de como a antropometria é aplicada em projetos de espaço e de mobiliário. Neste momento, a leitura de artigos publicados em congressos com resultados de pesquisas sobre o assunto contribuíram para melhor entendimento do assunto.

De volta à prática, a segunda etapa do trabalho foi a análise ergonômica do posto de trabalho. Cada aluno teve como meta reconhecer e analisar seu próprio ambiente e condições de trabalho em casa, além de especificar a locação dos móveis e objetos e as atividades referentes aos estudos de design de produto e gráfico, tais como as extensas horas de uso do computador, desenho, leitura e atividades manuais diversas.

Os critérios de análise do ambiente foram: insolação; iluminação, natural e artificial; ventilação, circulação de ar por aberturas como janelas e portas, e a proporcionada por ventiladores ou ar condicionado, visto que em Fortaleza o ambiente é regularmente quente; e qualidade sonora. Para diagnosticar os objetos e mobiliários existentes foi solicitado o desenho técnico em planta e elevações do lugar de trabalho em casa com layout e especificações, observando em que condições cada tarefa se realiza.

A terceira etapa, que prosseguiu a análise ergonômica realizada, foi a conjunção da antropometria individual, para entendimento da importância das medições de parâmetros humanos, na elaboração de uma proposta de transformação do posto de trabalho.

Tabela 1: Critérios de avaliação dos resultados

\begin{tabular}{|c|c|c|c|c|c|c|c|c|}
\hline Aluno & $\begin{array}{c}\text { Antropo } \\
\text { metria } \\
(1)\end{array}$ & $\begin{array}{c}\text { Atividade } \\
(1,5)\end{array}$ & $\begin{array}{l}\text { Análise } \\
\text { posto } \\
(1,5)\end{array}$ & $\begin{array}{c}\text { Ambiente } \\
\text { (1) }\end{array}$ & $\begin{array}{l}\text { Layout } \\
\text { (1) }\end{array}$ & $\begin{array}{c}\text { Readequação } \\
\text { das atividades } \\
\text { (1) }\end{array}$ & $\begin{array}{c}\text { Projeto } \\
\text { (3) }\end{array}$ & $\begin{array}{l}\text { Nota } \\
\text { final }\end{array}$ \\
\hline An. & - & 1 & 1 & 1 & 0,5 & 1 & 2,5 & 7,0 \\
\hline $\mathrm{Br}$. & - & 1 & 1,5 & 1 & 1 & 0,5 & 2,5 & 7,5 \\
\hline De. & 1 & 0,5 & 1,5 & 1 & 1 & 1 & 2,5 & 8,5 \\
\hline Gal. & 1 & 1,5 & 1,5 & 0,5 & 1 & 0,5 & 2,5 & 8,5 \\
\hline Gall. & 0,5 & 1 & 1 & 1 & 1 & 1 & 2 & 7,5 \\
\hline Gui. & 1 & 0,5 & 1,5 & 0,5 & 1 & 1 & 2,5 & 8,0 \\
\hline Is. & - & 1 & 1,5 & 1 & 1 & 1 & 2 & 7,5 \\
\hline Jos. & 1 & 1,5 & 1,5 & 0,5 & 0,5 & 1 & 2 & 8,0 \\
\hline La. & - & 0,5 & 1,5 & 1 & 1 & 1 & 2,5 & 8,0 \\
\hline Let. & - & 1 & 1,5 & 1 & 1 & 1 & 1,5 & 6,0 \\
\hline Lev. & 1 & 1,5 & 1,5 & 1 & 1 & 1 & 3 & 10 \\
\hline Lív. & 1 & 1,5 & 1,5 & 1 & 1 & 0,5 & 2 & 8,5 \\
\hline Lu & - & 1 & 1,5 & 1 & 0,5 & 1 & 2 & 7,0 \\
\hline M. K. & 1 & 1 & 1,5 & 0,5 & 1 & 0,5 & 2 & 7,5 \\
\hline
\end{tabular}




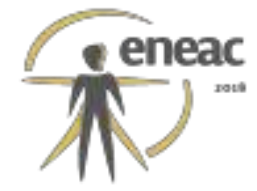

\begin{tabular}{|c|c|c|c|c|c|c|c|c|}
\hline Man. & 0,5 & 0,5 & 1,5 & 1 & 1 & 0,5 & 2 & 7,0 \\
\hline M. L. & 1 & 1 & 1,5 & 0,5 & 0,5 & 1 & 2 & 7,5 \\
\hline Mar. & 1 & 1,5 & 1,5 & 1 & 1 & 1 & 3 & 10 \\
\hline Mic. & 0,5 & 1,5 & 1,5 & 1 & 0,5 & 1 & 2 & 8,0 \\
\hline $\mathrm{Pa}$. & 0,5 & 1 & 1,5 & 0,5 & 0,5 & 0,5 & 2 & 6,5 \\
\hline P. J. & 1 & 1,5 & 1,5 & 1 & 1 & 0,5 & 3 & 9,5 \\
\hline Raf. & 1 & 1 & 1,5 & 1 & 1 & 0,5 & 2,5 & 8,5 \\
\hline Raq. & 1 & 1,5 & 1,5 & 1 & 1 & 0,5 & 2 & 8,5 \\
\hline Tha. & 1 & 1,5 & 1,5 & 1 & 1 & 1 & 3 & 10 \\
\hline
\end{tabular}

Fonte: Elaborado pelos autores, com base na pesquisa realizada

Para a avaliação foram especificados os seguintes critérios: 1) coerência antropométrica, onde foi verificado tanto as medidas de circulação e das atividades no espaço como a aplicação das medidas nos mobiliários; 2) análise das atividades; 3) análise do posto de trabalho; 4) transformação das qualidades do ambiente; 5) readequação do layout; 6) readequação das atividades; 7 ) projeto dos mobiliários e objetos, como mostra a Tabela 1.

\subsection{Classificação e Análise das Informações a partir dos Resultados Obtidos}

A partir dos resultados foram feitas análises dos vários tipos de interferências no ambiente, no layout, nos objetos e nas ações específicas de cada situação analisada. Uma ampla gama de atividades foi consideradas por serem executadas em um espaço, que era simultaneamente o ambiente de dormir, vestir, guardar objetos pessoais e objetos de estudo e o posto de trabalho, para desenvolver das ações demandadas pelo curso de design. Este aspecto de multiplicidade de atividades é comum a todos os trabalhos analisados.

Foram escolhidos três projetos para análise neste artigo. Os critérios de escolha foram: A qualidade do desenvolvimento do trabalho; a metodologia aplicada no processo de identificação dos problemas e busca de soluções; a utilização criativa da linguagem gráfica na apresentação da proposta; e o potencial de aplicação e interferência no ambiente real.

\subsubsection{Análise do Projeto 1}

No primeiro projeto, o aluno L. desenvolveu um processo de análise da situação problema. Um dos pontos críticos específico como início da análise foi a escassez de área útil. Neste sentido, foi pensado mais de um layout para estudo comparativo de possibilidades de rearranjos espaciais do mobiliário necessário às suas atividades. A forma de apresentação do trabalho demonstrou, além da criatividade do aluno, o envolvimento com a parte gráfica, que neste caso, não era foco principal, foi deixado livre para justamente se observar a atitude de cada aluno em aspectos que faziam parte do curso como um todo. 


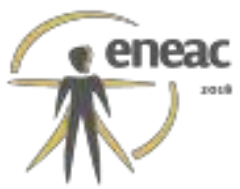

Figura 2 - Análise feita pelo aluno Lev. da situação problema e layouts desenvolvimentos analisados com o recurso gráfico.
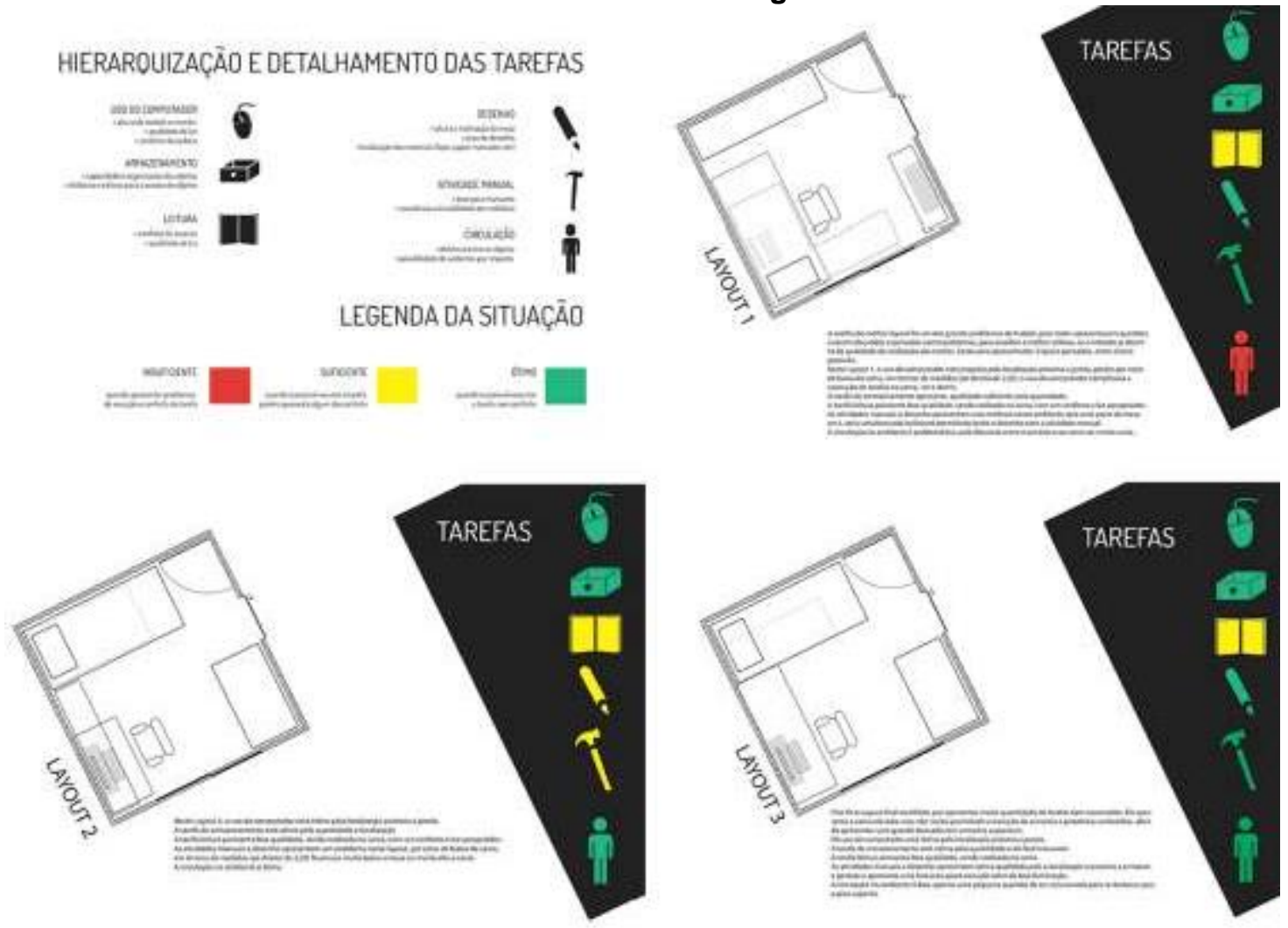

Fonte: Acervo do Aluno e da disciplina.

O aspecto mais relevante deste projeto foi que o aluno criou, com um pensamento vinculado ao design gráfico, uma metodologia onde, em primeiro lugar, fez o levantamento do ambiente, da situação real. O segundo passo foi a análise hierárquica das tarefas, onde foram criados ícones correspondentes a cada atividade e cores que representaram a qualidade da situação: verde como ótima, amarela como suficiente e vermelha como insuficiente (Figura 2). O terceiro passo foi a análise ergonômica do ambiente atual relacionada ao levantamento das medidas antropométricas pessoais. Por fim o aluno experimenta diferentes layouts (Figura 2) e analisa ergonomicamente cada um a partir da análise hierárquica das tarefas, até chegar na solução ótima (Figura 2).

\subsubsection{Análise do Projeto 2}

A aluna Mar. possuía condições apropriadas em termos de dimensionamento do espaço, mas em seu detalhado diagnóstico verificou que o layout não era favorável para as atividades e que era necessário resolver os problemas acústicos e térmicos. A circulação foi priorizada, o que direcionou o redesenho dos objetos e móveis no espaço.

Figura 3 - Comparativo entre a antiga situação em planta e corte, e a nova proposta da Aluna Mar. 

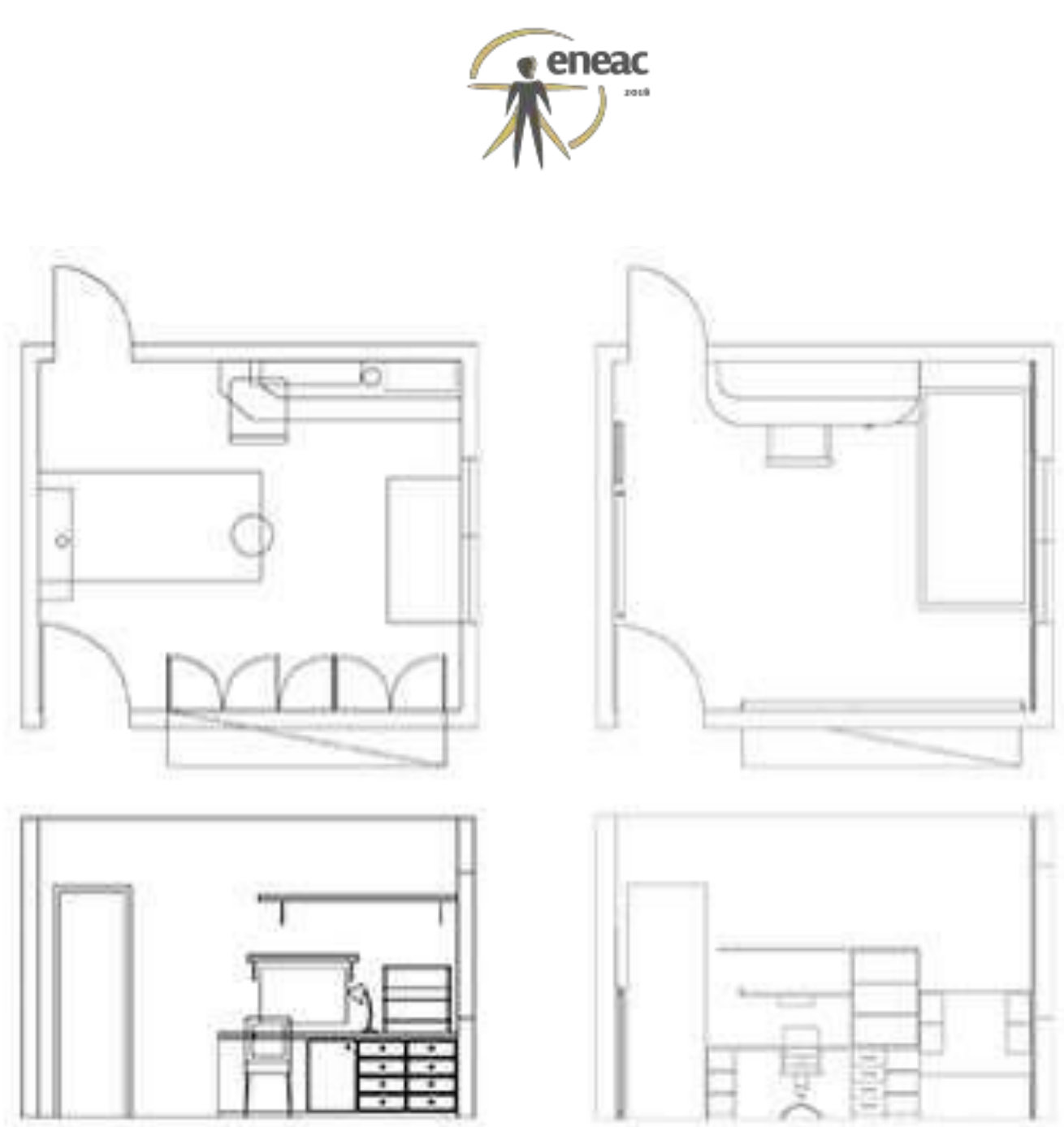

Fonte: Acervo da Aluna e da disciplina.

As soluções desse projeto se destacaram pelo detalhamento de todos os mobiliários e a adequação de suas disposições no ambiente. Com a mesma minúcia do diagnóstico, as soluções foram propostas com precisão em cada particularidade sempre com o cuidado de relacionar os aspectos físicos do lugar com as atividades praticadas e com os objetos.

Figura 4 - Imagens renderizadas da proposta de mobiliário da aluna Mar.

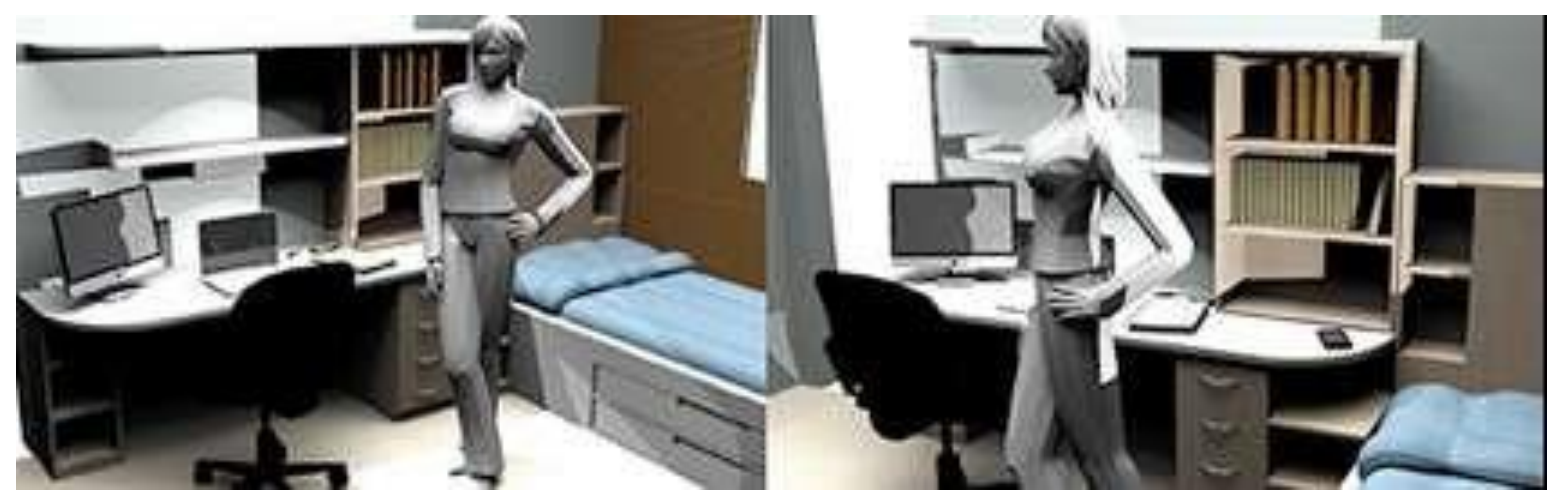

Fonte: Acervo da Aluna e da disciplina. 


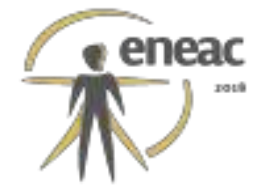

\subsubsection{Análise do Projeto 3}

No Projeto 3, a aluna Tha. realizou a análise da situação problema, com base no exame das condições espaciais do local atual (Figuras 5 ) partindo dos dados antropométricos pessoais (baixa estatura), além dos critérios previamente estabelecidos de iluminação, ruído, temperatura ambiente. Dada a análise geral do ambiente e especificamente do posto de trabalho, inclusive a localização espacial deste, o trabalho se destaca por alcançar as três medidas de usabilidade de um ambiente, sejam elas: a eficácia funcional, a eficiência antropométrica e a satisfação pessoal.

Figura 5 - Perspectivas do diagnóstico de situação do ambiente da aluna Tha.
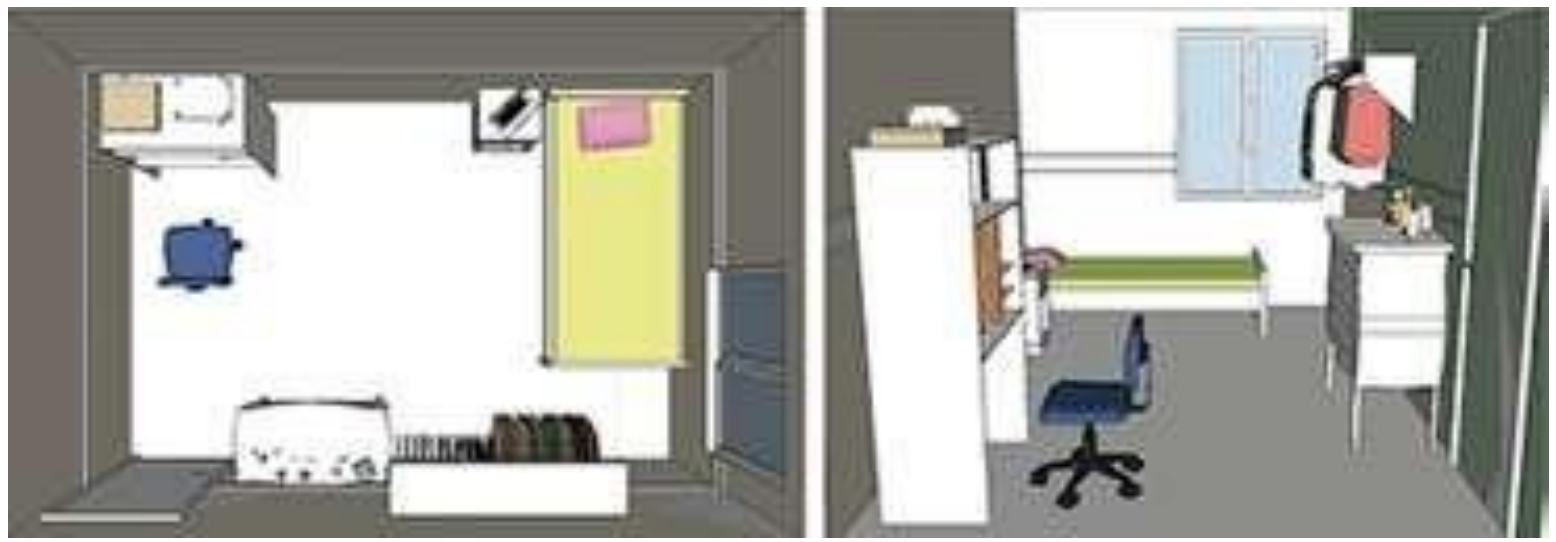

Fonte: Acervo da Aluna e da disciplina.

Para eficácia funcional e antropométrica, fez uso dos critérios de estudo do layout para melhor determinar as condições do posto de trabalho, bem como dos princípios ergonômicos dos objetos componentes do referido posto. Como resultado para adequação do ambiente e melhoria das condições de uso do posto de trabalho foram feitos os seguintes ajustes:

- Elevação da cama em 1,60m, para maior aproveitamento de espaço;

- Substituição dos vidros da janela por vidro anti-ruído de $20 \mathrm{~mm}$ de espessura;

- Exclusão da estante (os livros e alguns dos objetos anteriormente por ela comportados são transferidos para um nicho de $2,86 \mathrm{~m}$ de comprimento);

- Adição de uma longa bancada em "L", com $66 \mathrm{~cm}$ de altura e com espaço suficiente para quaisquer atividades;

- Elevação do monitor do computador em $7 \mathrm{~cm}$, para que o centro da tela esteja no nível dos olhos da usuária;

- Na bancada, adição de quatro gavetas numa extremidade (para guardar quaisquer objetos) e de uma gaveta translúcida na superfície (para, simultaneamente guardar e expor ferramentas de trabalho);

- Adição de uma lâmpada embaixo da cama para que a área de trabalho logo abaixo desta tenha iluminação, se necessário; 


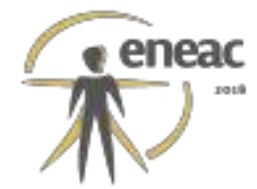

- Adição de um quadro branco para anotar eventuais ideias, lembretes e afins ou para usar como mural;

- Manutenção do desenho da arara de roupas, alongando em $72 \mathrm{~cm}$;

- Substituição da cômoda anterior por uma cômoda baixa, abaixo da arara de roupas;

- Adição de uma cortina "roll-on" opaca para diminuir a incidência de luz em até $70 \%$;

- Adição de um interruptor próximo à cama para que a proprietária não precise descer da cama para desligar as luzes;

- Adição de uma arandela de luz branda próximo à cama;

- Manutenção da cadeira ajustável e giratória, pois esta já era adequada para a proprietária.

Figura 6 - Perspectivas do projeto da aluna Tha.

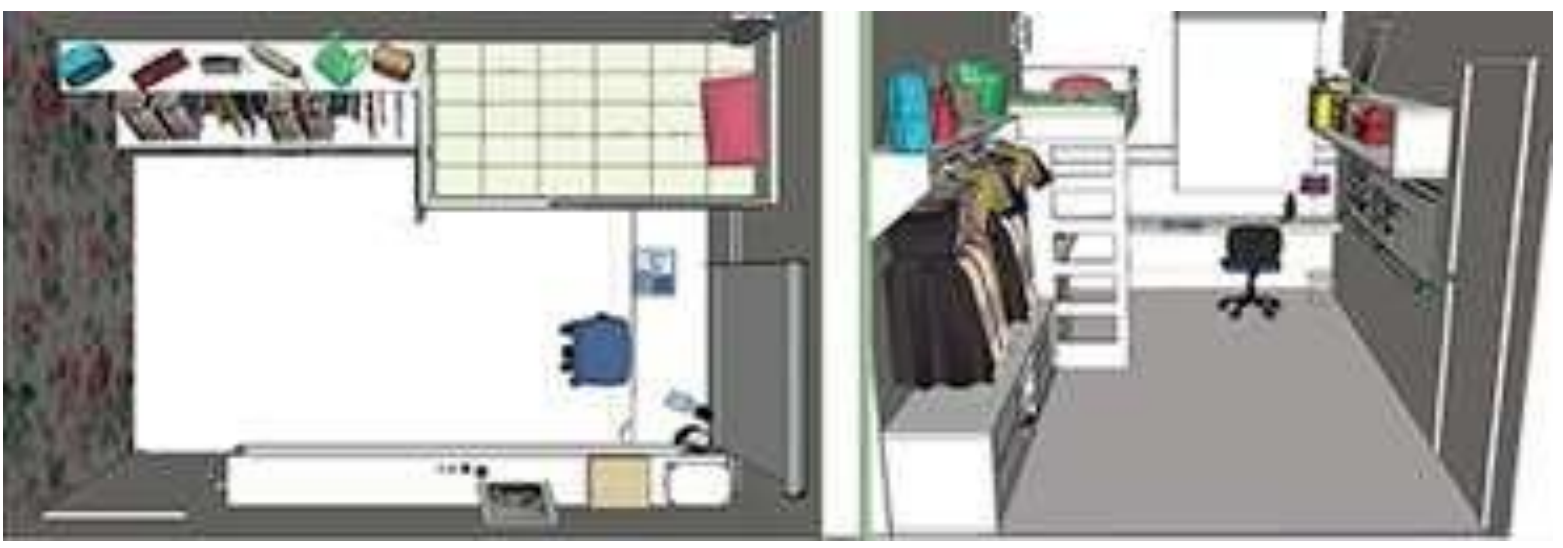

Fonte: Acervo da Aluna e da disciplina.

Com este estudo, a solução encontrada para o ambiente (Figura 6) de uma forma geral, bem como para o posto de trabalho, especificamente, obteve resultados que: ampliaram a área de circulação do ambiente; maior aproveitamento e mais espaço de armazenamento tanto de livros, quanto de materiais de trabalho e de roupas; e ampliaram também a área de trabalho dando condições para outras atividades antes limitadas.

\section{CONSIDERAÇÕES FINAIS}

Os resultados da disciplina foram avaliados, tanto nos aspectos da metodologia de ensino aplicada quanto à condição de material produzido pelos alunos em exercício prático de utilização dos princípios ergonômicos. Foi considerada e enfatizada também a conscientização da importância do estudo da Antropometria, que abarca a diversidade de dimensionamento e as necessidades espaciais das pessoas em relação às tarefas que executam.

Diante das limitações de tempo e da condição em que se encontra a disciplina em fase de estruturação, verificamos que:

- A disciplina atingiu os objetivos propostos; 


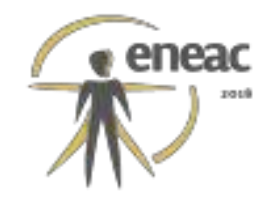

- Embora com algumas limitações, os alunos atingiram um grau satisfatório de entendimento das questões ergonômicas tratadas;

- $\quad$ Foi positiva a aplicação de um estudo de características da pesquisa empírica, em que cada aluno, de maneira a analisar suas próprias tarefas/atividades de forma a reconhecê-las, identificá-las, classificá-las e diagnosticar as condições ergonômicas espaciais, do mobiliário e dos equipamentos do seu posto de trabalho.

- A aplicação dos princípios ergonômicos referenciados, quanto o estudo da Antropometria também referenciada quanto auferida pelo grupo, fez com que, de posse dos resultados dos seus trabalhos, alguns alunos passassem a adotar as mudanças propostas na realidade, como mudança de layout, de mobiliário ou ainda de pequenos detalhes.

Como já foi citado, a limitação em termos de estruturação da disciplina, oferecida pela primeira vez, e também por isso embates que tivemos com a turma, passaram a ser motivação para o desenvolvimento e aprimoramento da disciplina, inclusive, podendo sugerir que alguns trabalhos possam ser integrados a outras disciplinas, como as de "Projeto de Produto 1" e "Materiais e Processos 1", para que o aprofundamento das questões conceituais possam ser mais amplamente discutidas e assimiladas antes e durante o processo de trabalho de campo. A articulação com outras disciplinas do mesmo semestre também podem criar oportunidades de ampliação das condições de discussão sob vários enfoques, bem como potencializar e intensificar a transdisciplinaridade que requer a solução de situações problema.

\section{REFERÊNCIAS BIBLIOGRÁFICAS}

ASSOCIAÇÃO BRASILEIRA DE NORMAS TÉCNICAS. NBR 9050: Acessibilidade a edificações, espaço, mobiliário, e equipamentos urbanos. Rio de Janeiro: ABNT, 2005.

BARBIER, R. A pesquisa-ação. Brasília: Plano, 2002.

DREYFUSS, Henry. As medidas do homem e da mulher. Bookman. Porto Alegre, 2005.

DUL, J.; WEERDMEESTER. Ergonomia Prática. Trad. Itiro lida. São Paulo: Edgard Blücher, 2012.

GOMES FILHO, João. Ergonomia do Objeto: sistema técnico de leitura ergonômica. $2^{\mathrm{a}}$ ed. ver. amp. São Paulo: Escrituras Editora, 2010.

GRANDJEAN, Etienne. Manual de ergonomia: adaptando o trabalho ao homem. Bookman: Porto alegre, 1998.

IIDA, Itiro. Ergonomia: projeto e produção. São Paulo: Edgard Blücher, 2005.

LAVILLE, Antoine. Ergonomia. São Paulo: EPU, Edusp, 1997.

MORAES, Anamaria; MONT'ALVÃO Cláudia. Ergonomia: Conceitos e Aplicações. Rio de Janeiro: 2AB, 2010.

PANERO, Julius, ZELNIK, Martin. Dimensionamento humano para espaços interiores. Gustavo Gilli, Barcelona, 2003.

PHEASANT, Steven. Bodyspace. Anthropometry, Ergonomics and the Design of Work. Londres: Taylor \& Francis, 1997.

SCHÖN, Donald A. Educando o profissional reflexivo: um novo design para o ensino e a aprendizagem. Tradução Roberto Cataldo Costa. Artmed, Porto Alegre, 2000.

TRIPP, David. Pesquisa Ação: uma Introdução Metodológica. Trad. Lélio Lourenço de Oliveira. Educação e Pesquisa, São Paulo, v. 31, n. 3, p. 443-466, set./dez. 2005. 